\title{
Long-term retainment of some chromosomal inversions in a local population of Belgica antarctica Jacobs (Diptera, Chironomidae)
}

\author{
Paraskeva Michailova ${ }^{1}$, Julia Ilkova ${ }^{1}$, Pavlo Kovalenko ${ }^{2}$, Artem Dzhulai ${ }^{3}$, \\ Iryna Kozeretska ${ }^{3 *}$
}

${ }^{1}$ Institute of Biodiversity and Ecosystem Research, Bulgarian Academy of Sciences, Tzar Osvoboditel b. 1, Sofia, Bulgaria

${ }^{2}$ State Institution «Institute for evolutionary ecology», National Academy of Sciences of Ukraine, Lebedeva str. 37, Kyiv, Ukraine

${ }^{3}$ National Antarctic Scientific Center of Ukraine, Taras Shevchenko b. 16, Kyiv, Ukraine

\begin{abstract}
Genome of antarctic endemic Belgica antarctica Jacobs has been sequenced. However, no set of inversion diagnostic markers has ever been assigned for the species. Using the classical method of polytene chromosome squash preparation, we found three heterozygous inversions located on the second (two heterozygous inversions) and third chromosomes (one heterozygous inversion) in the Belgica antarctica population of a cape of Wiencke Island, $500 \mathrm{~m}$ to SW from Port Lockroy. The chromosome set and chromosome variability did not differ from those described in the literature (Atchley and Davis 1979). Every salivary gland chromosome had its own markers by which it can be determined. However, we did not find a sex-linked inversion on chromosome III and heterozygous inversion on chromosome I, reported in earlier studies. For the first time, we observed a strong heterochromatin band in chromosome III at the telomere of one arm. Our data show not only the stability of the described inversions in the population but also the usefulness of the squash preparation technique in the studies of genetic variability of Belgica antarctica in present time.
\end{abstract}

Key words: Antarctic midge, salivary gland chromosomes, heterozygous inversion, dark band

DOI: $10.5817 / C P R 2021-1-3$

\section{Introduction}

Chromosome inversions are structural mutations known to be widespread in many insect species. Even more, in some insects, they can be quite large (up to
$22 \mathrm{Mb}$ in Anopheles gambiae) (White et al. 2007). They often occur as a balance polymorphism and may play a significant role in speciation (King 1993). The proc-

Received December 17, 2020, accepted May 10, 2021.

*Corresponding author: I. A. Kozeretska <iryna.kozeretska@gmail.com>

Acknowledgements: The authors would like to express their gratitude to the two anonymous reviewers whose comments and recommendations served to improve the manuscript. The study was carried out in the framework of the State Special-Purpose Research Program in Antarctica for 2011-2020 (Ukraine). 
ess producing inversions is thought to be one of the main mechanisms of genome reorganization, although it is not yet known what factors induce them or cause dynamic changes in their frequencies in natural populations (Kirkpatrick 2010). Inversions are believed to have adaptive qualities due to suppression of recombination in the heterozygous state when heterozygous specimens are favored by stabilizing selection (Wellenreuther and Bernatchez 2018). Recently, the rapidly developing Pool-Seq technology applied to a highly diverse variety of species allows to study inversion events, yet it can not derive inversion frequencies in species with insufficiently studied genomes (Kapun et al. 2014). In such cases, cytological study of polytene chromosomes remains a valuable tool. This is true also for the Antarctic endemic Belgica antarctica Jacobs, which despite its sequenced genome (Kelley et al. 2014) has yet to be assigned a set of inversion diagnostic markers, as we could not find any data in the literature on this matter.

$B$. antarctica has a chromosome complement of $2 n=6$. The first study of polytene chromosomes in this species from the Danco Coast population of the Palmer Peninsula $\left(64^{\circ} 49^{\prime} \mathrm{S}\right)$ recorded the presence of a large inversion in the chromosome carrying the nucleolus. It begined several bands before the nucleolus and ended a few bands from the end of the chromosome thus spanning more than a half of the chromosome (Martin 1962). The same author established a small inversion in chromosome III. Later, five chromosome inversions were detected in larvae of the species collected from the same area (Atchley and Davis 1979), including the two inversions described by Martin (1962). In addition, Atchley and Davis (1979) recorded two large heterozygous inversions in chromosome II named (A and B) occupying $27 \%$ and $23 \%$ of the chromosome, respectively. In chromosome III they also described two inversions (C and $\mathrm{D})$, one of which they defined as sex-linked and al- ways heterozygous in males.

The recent decades brought to the Antarctic region substantial environmental changes in climate as well as in anthropogenic impact (Bargagli 2005, Turner et al. 2009). Thus, Contador et al. (2020), based on the climatic changes alongside the Antarctic Peninsula, foresau that the range of the chironomid midge Parochlus steinenii would grow to include even the coastal ice-free areas in parts of continental Antarctica. Potts et al. (2020) demonstrated that $B$. antarctica abundance depends both on the biotic and abiotic environmental factors which themselves follow the climate changes, thus showing that the midge actively chooses its habitat conditions. According to Benoit et al. (2007), at temperatures higher than $15^{\circ} \mathrm{C}$ the imagoes of $B$. antarctica actively lose water and undergo dehydration stress. Moreover, dehydration of larvae confers subsequent desiccation and freeze tolerance of the species as shown by Yoshida et al. (2021) recently. Generally, B. antarcica is considered resistant to cryoprotective dehydration, freezing and osmotic stress (Elnitsky et al. 2008, 2009). Recently, Finch et al. (2020) noted potential effect of the above mentioned stresses on reproduction and several genes' expression. However, the effects of these factors on the inversion polymorphism of B. antarctica are generally unknown (Finch et al. 2020, Potts et al. 2020, Contador et al. 2020).

According to a study of $28 \mathrm{~S}$ ribosomal DNA and the mitochondrial gene cytochrome c oxidase 1 (cox1) of B. antarctica, the population on Goudier Island Port Lockroy, west coast of Antarctic Peninsula $\left(64^{\circ} 49^{\prime} \mathrm{S}, 63^{\circ} 29^{\prime} \mathrm{W}\right)$ (4 samples) belongs to haplotype $\mathrm{C}$ (Allegrucci et al. 2012). As to inversions, the midges of Port Lockroy studied by Atchley and Davis (1979) were polymorphic as to inversion frequencies. Thus, homogenous by molecular markers insects can potentially be heterogeneous in regards to inversions. 
Ice-free habitats in Maritime Antarctica are fragmented and isolated from each other (Allegrucci et al. 2012). The fragmentation interrupts movement of animals and gene flow between populations of the animals. It is the process of genetic divergence and speciation in isolated populations, which represent an important evolutionary mechanism (Allegrucci et al. 2012).

The goal of this study is to trace the cytogenetic variability of the species from the same localities where this variability was first studied by Atchley and Davis
(1979) and to investigate to what extent this variability, described by the above authors, has been preserved. Our hypothesis was that the changes in biotic and abiotic factors arising from global warming and anthropogenic impact could induce chromosome aberrations. To test this assumption, chromosomal variability of the salivary gland chromosomes of $B$. antarctica from the Wiencke Island, $500 \mathrm{~m}$ to SW from Port Lockroy was analyzed and compared with those found by Atchley and Davis (1979).

\section{Material and Methods}

\section{Study plots}

The collections of B.antarctica were made during the austral summer on February $3^{\text {rd }}, 2020$ on a cape of Wiencke Island,
$500 \mathrm{~m}$ to SW from Port Lockroy on a terrace covered by Sanionia sp. at $32 \mathrm{~m}$ a.s.l., 64.82907 S, 63.48868 W (Fig. 1).

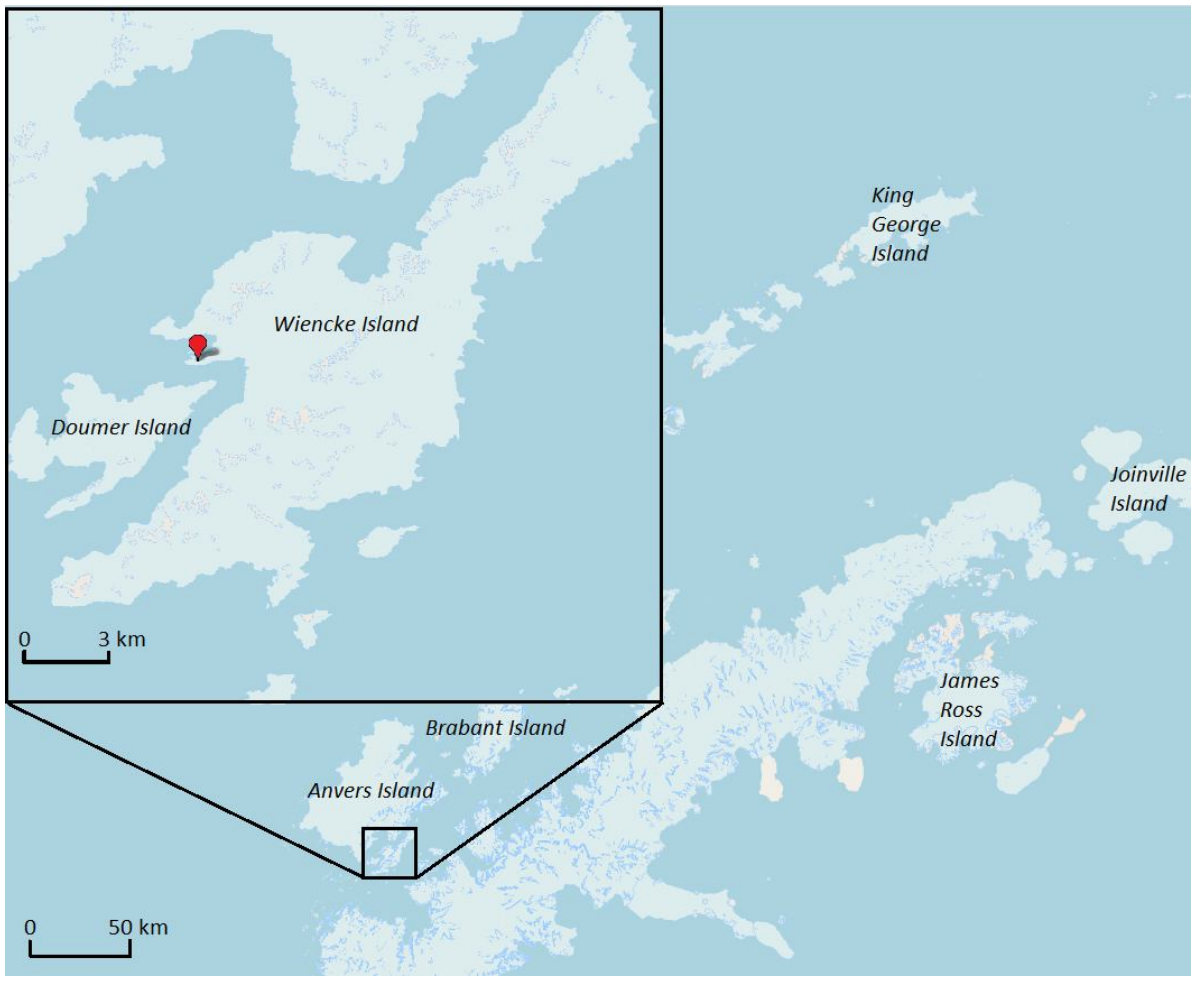

Fig. 1. Map indicating location of the sampling area for the collection of Belgica antarctica larvae. 


\section{Materials}

All examined specimens were the $4^{\text {th }}$ larva stage preserved in 3:1 ethyl alcohol acetic acid fixative. The samples were trans-

\section{Methods}

Chromosomal preparations were made by 8 individuals. The salivary gland chromosome preparations were done according to Michailova (1989) and were kept at the Institute of Biodiversity and Ecosystem Research, Bulgarian Academy of Sciences. Chromosome preparations were prepared

\section{Results}

The chromosome set of the species from Wiencke Island, $500 \mathrm{~m}$ to SW from Port Lockroy is $2 \mathrm{n}=6$ (Figs. 2, 3, 4, 5) which coincides with data of Atchley and Davis (1979).

Cytogenetic marker of chromosome I is the Balbiani Ring (BR) located near to the left arm (L) of the chromosome. The Nucleolar Organizer Region (NOR) is in the middle of the right arm (R) (Fig. 2). No heterozygous inversion has found in this chromosome, despite a large one reported by Martin (1962) in 12.3\% cases (10 out of 81), Atchley and Davis (1979) in $0.08 \%$ of midges (ona out of 1182 sampled) and Martin (1962) in $12.3 \%$ cases (10 out of 81).

Chromosome II is recognized by $\mathrm{Nu}-$ cleolar Organizer Region located in the middle of the chromosome (Fig. 3). The designation of dark band by Atchley and Davis (1979) of the left arm of the chromosome, in our material is seen in $25 \%$ of the studied individuals, but not in all cells (Fig. 7). In most individuals we observed either heterozygous aberration A (25\%) ported to Ukraine on ice. Upon arrival, the ethyl alcohol - acetic acid fixative was changed.

from each individual which was determined by external morphology of larva, using the Usher and Edwards (1984) description. The polytene chromosomes and chromosome aberrations were identified according to Atchley and Davis (1979).

(Fig. 6) or heterozygous inversion B $(12.5 \%)$ (Fig. 7). The heterozygous aberrations (A and B) occurred in $37.5 \%$ (see Figs. 3,8 ) (the names of these aberrations are given according to Atchley and Davis (1979), located near the telomeres of the chromosome II (see Figs. 3, 6, 7, 8). Thus, inversions first identified by Atchley and Davis (1979) do still exist in B. antarctica populations, perhaps indicating their ancient origin.

A marker of chromosome III is the Nucleolar Organizer Region located on the left arm (L) of the chromosome (Figs. 4, 5). At this telomere, for the first time, we observed a dark band in $12.5 \%$ of the studied individuals, but not in all cells (Fig. 4). This phenomenon was not described by Atchley and Davis (1979). Also, we did not see a large sex-linked heterozygous inversion in males, found by the above authors. The small inversion near the telomere of right arm occurred with frequency (25\%) (Fig. 8) and announced also by Atchley and Davis (1979). 


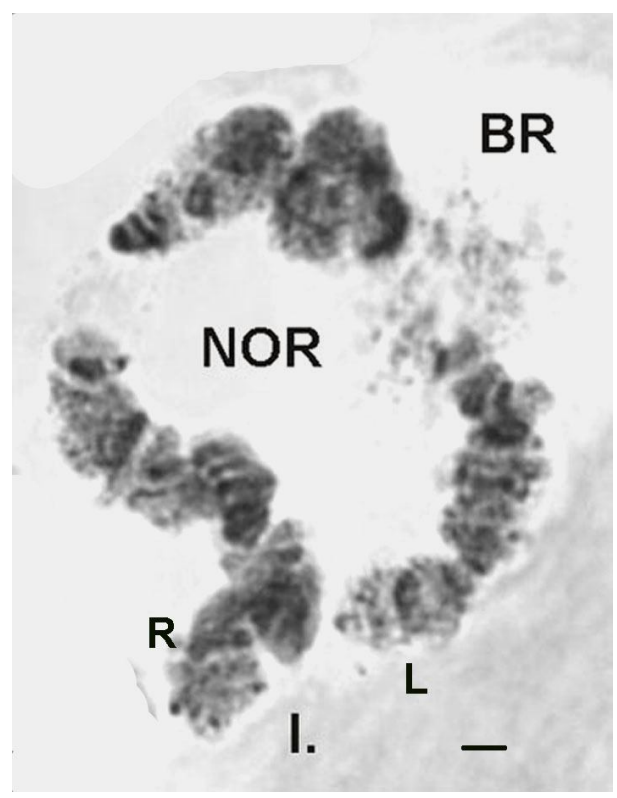

Fig. 2. Polytene chromosomes I with Balbiani ring (BR) and Nucleolar organizer (NOR). Bar $10 \mu \mathrm{m}$.

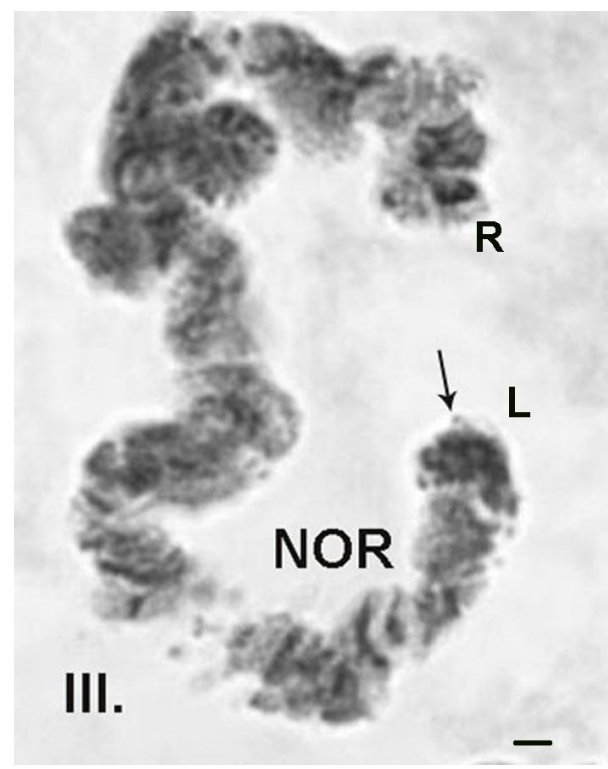

Fig. 4. Polytene chromosome III with $\mathrm{Nu}-$ cleolar Organizer Region (NOR) and dark band at one telomere of the chromosome. Bar $10 \mu \mathrm{m}$.

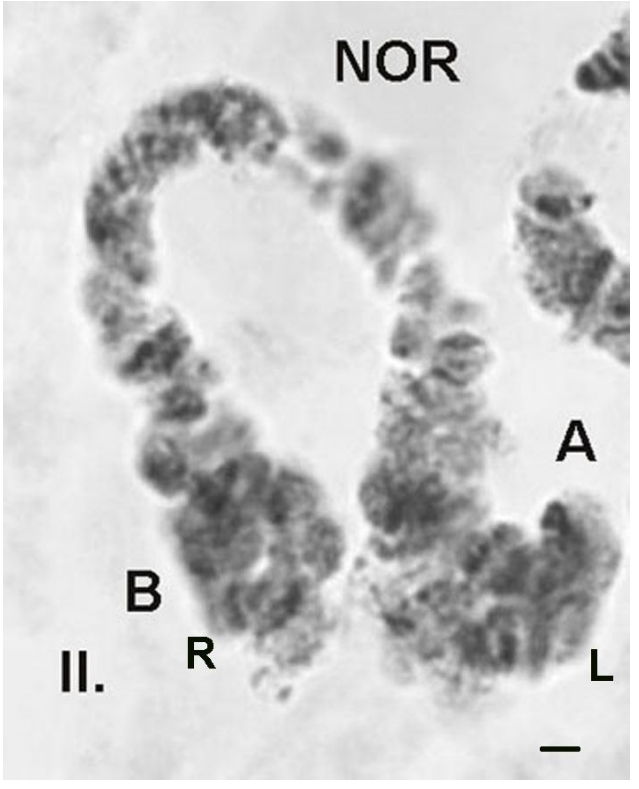

Fig. 3. Polytene chromosome II with Nucleolar Organizer Region (NOR) and heterozygous inversions ( $\mathrm{A}$ and $\mathrm{B}$ ) at the telomere of the chromosome. Bar $10 \mu \mathrm{m}$.

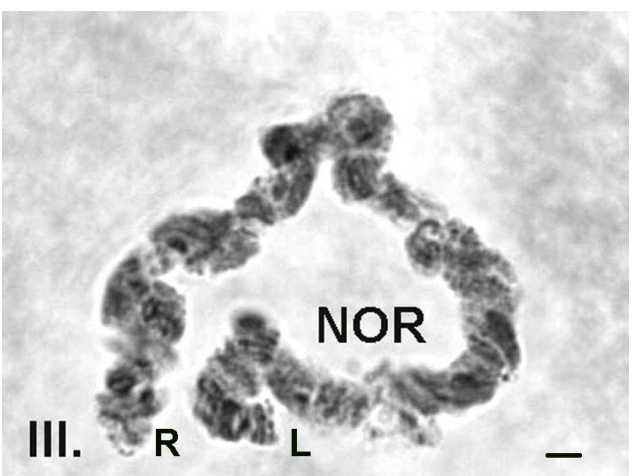

Fig. 5. Polytene chromosomes III with $\mathrm{Nu}-$ cleolar Organizer Region (NOR) and without dark band. Bar $10 \mu \mathrm{m}$. 


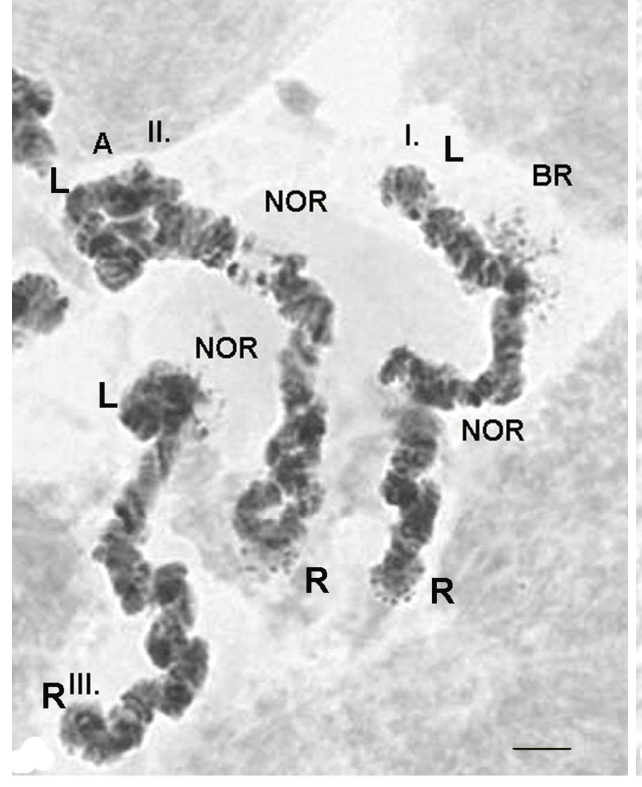

Fig. 6. Polytene chromosomes I, II and III plus a heterozygous inversion (A) at one telomere of chromosome II. Bar $10 \mu \mathrm{m}$.

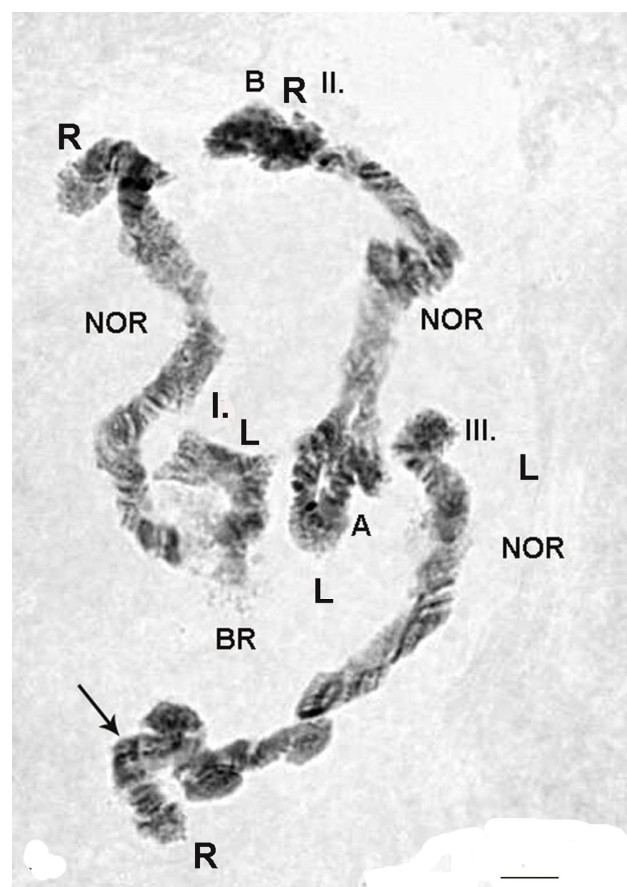

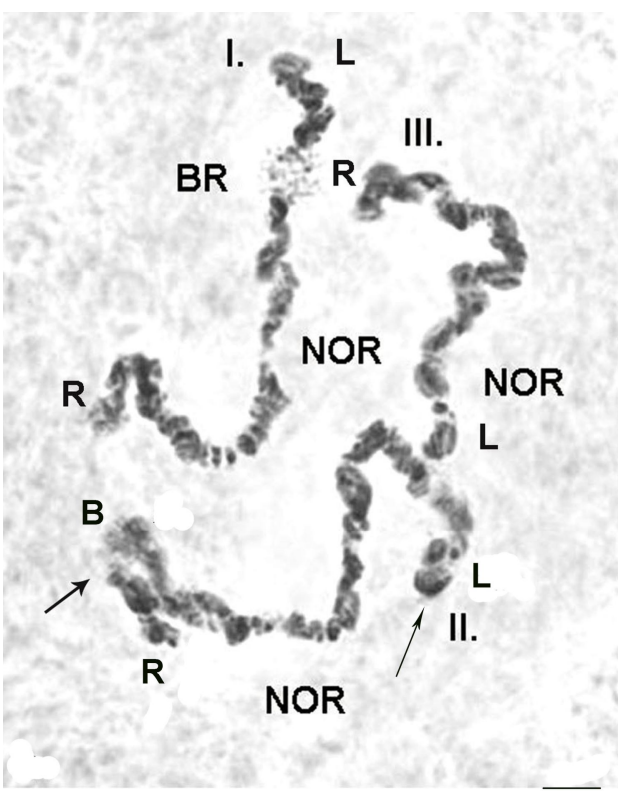

Fig. 7. Polytene chromosomes I, II and III with very low degree of polyteny, a heterozygous inversions $\mathrm{B}$ and a dark band at the telomere region. Bar $10 \mu \mathrm{m}$.

Fig. 8. Polytene chromosomes I, II and III, with a small heterozygous inversion at the telomere of chromosome III and heterozygous inversions $(\mathrm{A}, \mathrm{B})$ at the telomere of the chromosome II. Bar $10 \mu \mathrm{m}$. 


\section{Discussion}

During the last decades, significant changes have been recorded in environmental factors such as temperature, moisture, soil nutrients, along with biotic interactions within and between species along the Antarctic Peninsula. These changes have been attributed both to the climate warming and the anthropogenic influence (Bargagli 2005, Turner et al. 2009, Potts et al. 2020). In response to environmental factors, some species are known to exhibit a so-called clinal variation in the frequency and qualitative content of chromosome inversions, explained by the adaptation to different environmental factors (Hoffmann and Rieseberg 2008). Inversion polymorphism of $B$. antarctica has been the subject of only a few studies (Kozeretska et al. 2021). Atchley and Davis (1979) assumed that the heterozygous inversions observed in their investigation had some adaptive value through the mechanism which promoted heterozygosity and reduced recombination. However, when they applied a three-factor analysis of variance with interaction on each larval character where locality, sex, and chromosomal inversion heterozygote type, a series of one-way multivariate analyses of variance they did not find any relationship between chromosomal heterozygosity and ecological conditions in the localities they studied. They explained this finding by great habitat alterations in the sampled localities over short periods of time, by inbreeding, and by not suitable statistical approaches. We also observed a large chromosomal variability in this species from the studied locality. Interestingly, analysis of the $28 \mathrm{~S}$ ribosomal DNA and the mitochondrial gene cytochrome $\mathrm{c}$ oxidase 1 (cox1) by Allegrucci et al. (2012) highlighted only one haplotype in $B$. antarctica populations from the same region. Our results show three out of five inversions described by Atchley and Davis (1979) in the same population they studied. Therefore, our hypothesis that the change in habitat can lead to changes in inversion polymorphism was not confirmed, at least for the chromosomes we studied. Perhaps these inversions allow the species to have adaptation capabilities which are not connected to changes in the environment now seen within the range of $B$. antarctica. The limited quantity of study material did not allow us to discuss either the overall diversity of inversions or their frequencies. Yet we can confirm that forty years after Atchley and Davis (1979) conducted their study, three inversions they found are still present in the population of B. antarctica. Therefore, the fact that the three inversions have been preserved in the species for about 40 years confirm their adaptive value and stability against the habitat changes, at least for the levels so far observed. The results suggest the importance of applying the method of polytene chromosomes analysis to shed some light on interesting aspects of the genetic variability of $B$. antarctica populations locally and over the whole of its range.

\section{References}

Allegrucci, G., Carchini, G., Convey, P. and Sbordoni, V. (2012): Evolutionary geographic relationships among ortocladine chironomid midges from maritime Antarctic and sub-Antarctic islands. Biological Journal of the Linnean Society, 106: 258-274.

Atchley, W., Davis, B. (1979): Chromosomal variability in the Antarctic Insect, Belgica antarctica (Diptera: Chironomidae). Annals of the Entomological Society of America, 72: 246252 . 
BARgagli, R. (2005): Antarctic Ecosystems: Environmental Contamination, Climate Change, and Human Impact. Springer, Berlin, Heidelberg, 398 p.

Benoit, J. B., Lopez-Martinez, G., Elnitsky, M. A., Lee, R. E. JR. and Denlinger, D. L. (2007): Mechanisms to reduce dehydration stress in the Antarctic midge, Belgica antarctica. Journal of Insect Physiology, 53: 656-667.

Contador, T., GaÑan, M., Bizama, G., Fuentes-Jaque, G., Morales, L., Rendoll, J., Simões, F., Kennedy, J., Rozzi, R. and Convey, P. (2020): Assessing distribution shifts and ecophysiological characteristics of the only Antarctic winged midge under climate change scenarios. Scientific Reports, 10: 9087.

Elnitsky, M. A., Hayward, S. A. L., Rinehart, J. P., Denlinger, D. L. and Lee, R. E. (2008): Cryoprotective dehydration and the resistance to inoculative freezing in the Antarctic midge, Belgica antarctica. Journal of Experimental Biology, 211: 524-530.

Elnitsky, M. A., Benoit, J. B., Lopez-Martinez, G., Denlinger, D. L. and Lee, R. E. (2009): Osmoregulation and salinity tolerance in the Antarctic midge, Belgica antarctica: seawater exposure confers enhanced tolerance to freezing and dehydration. Journal of Experimental Biology, 212: 2864-2871.

Finch, G., Nandyal, S., Perretta, C., Nandyal, S., Rosendale, A., Holmes, C., Gantz, J. D., Spacht, D., Bailey, S., Chen, X., Jeannet Oyen, K., Didion, E., Chakraborty, S., Lee, R., Denlinger, D., Matter, S., Attardo, G., Weirauch, M. and Benoit, J. (2020): Multi-level analysis of reproduction in an Antarctic midge identifies female and male accessory gland products that are altered by larval stress and impact progeny viability. Scientific Reports, 10: 19791.

Hoffmann, A. A., Rieseberg, L. H. (2008): Revisiting the impact of inversions in evolution: From population genetic markers to drivers of adaptive shifts and speciation? Annual Review of Ecology, Evolution, and Systematics, 39: 21-42.

Kapun, M., van Schalkwyk, H., McAllister, B., Flatt, T. and Schlötterer, C. (2014): Inference of chromosomal inversion dynamics from Pool-Seq data in natural and laboratory populations of Drosophila melanogaster. Molecular Ecology, 23(7): 1813-1827.

Kelley, J., Peyton, J., Fiston-Lavier, A. S., Teets, N. M., Yee, MC., Johnson, J. S., Bustamante, C. D., Lee, R. E. and Denlinger, D. L. (2014): Compact genome of the Antarctic midge is likely an adaptation to an extreme environment. Nature Communications, 5: 4611.

KING, M. (1993): Species Evolution. The Role of chromosome changes. Cambridgte University Press, New York, pp. 1-322.

KIRKPATRICK, M. (2010): How and why chromosome inversions evolve. PLOS Biology, 8(9): e1000501.

Kozeretska, I., Serga, S., Kovalenko, P., Gorobchyshyn, V. and Convey P. (2021): Belgica antarctica (Diptera: Chironomidae): A natural model organism for extreme environments. Insect Science, 0: 1-19. https://doi.org/10.1111/1744-7917.12925

MARTIN, J. (1962): Inversion polymorphism in an Antarctic species living in a simple environment. The American Naturalist, 96: 317-318.

Michailova, P. (1989): The polytene chromosomes and their significance for the systematics of family Chironomidae, Diptera. Acta Zoologica Fennica, 186: 1-107.

Potts, L., Gantz, J. D., Kawarasaki, Y., Philip, B., Gonthier, D., Law, A., Moe, L., Unrine, J., Mcculley, R., Lee, R., Denlinger, D. and Teets, N. (2020): Environmental factors influencing fine-scale distribution of Antarctica's only endemic insect. Oecologia, 194: 529539.

Turner, J., Bindschadler, R., Convey, P., Di Prisco, G., Fahrbach, E., Gutt, J., Hodgson, D., Mayewski, P. and Summerhayes, C. (2009): Antarctic Climate Change and the Environment A contribution to the international polar year 2007-2008. SCAR \& Scott Polar Research Institute, Cambridge, $526 \mathrm{p}$.

Usher, M., EdwARDS, M. (1984): A dipteran fauna south of the Antarctic Circle: Belgica antarctica (Chironomidae) with a description of its larva. Biological Journal of the Linnean Society, 23(1): 19-31. 
Wellenreuther, M., Bernatchez, L. (2018): Eco-evolutionary genomics of chromosomal inversions. Trends in Ecology and Evolution, 33: 427-440.

White, B. J., Hahn, M. W., Pombi, M., Cassone, B. J., Lobo, N. F, Simar, F. and Besansky, N. J. (2007): Localization of candidate regions maintaining a common polymorphic inversion (2La) in Anopheles gambiae. PLOS Genetics, 3(12): e217.

Yoshida, M., Lee, R. E., Denlinger, D. L. and Goto, S. G. (2021): Expression of aquaporins in response to distinct dehydration stresses that confer stress tolerance in the Antarctic midge Belgica antarctica. Comparative Biochemistry and Physiology Part A: Molecular \& Integrative Physiology, 256: 110928. 